\title{
O novo ciclo da medicina geral e familiar
}

Paulo Santos, ${ }^{*}$ Tiago Maricoto,* Alberto Hespanhol,* Rui Nogueira*

Tudo evolui; não há realidades eternas: tal como não há verdades absolutas. Friedrich Nietzsche

A Associação Portuguesa de Medicina Geral e Familiar publica ininterruptamente a REvISTA Portuguesa de Medicina Geral e Familiar desde 1984, assumindo-a como órgão oficial de publicação científica. Ao longo destes anos, o esforço de rigor e isenção levado a efeito pelas sucessivas direções editoriais da Revista contribuíram significativamente para o desenvolvimento da especialidade de medicina geral e familiar em Portugal e dos cuidados de saúde primários, em geral.

Nem sempre foi assim. Há uns anos atrás, a associação chamava-se Associação Portuguesa dos Médicos de Clínica Geral. E a revista chamava-se Revista PoRTUgueSA DE ClínICA GeRAL.

Mas tudo evolui. A instituição da carreira médica de Clínica Geral, no início dos anos 80, foi evoluindo para a estruturação do corpo de competências da nossa especialidade, hoje completamente distinta dos antigos serviços médico-sociais e mesmo dos centros de saúde criados pelo Despacho Normativo n. ${ }^{\circ} 97 / 83$, de 22 de abril.

Os anos 90 trouxeram a capacidade de inovar para melhorar a saúde nos diferentes projetos testados um pouco por todo o país, projeto alfa, regimes remuneratórios experimentais ${ }^{1}$ e projeto tubo-de-ensaio, ${ }^{2}$ até aos centros de saúde de terceira geração ${ }^{3}$ que se materializaram na reforma dos cuidados de saúde primários de 2006 e instituição das Unidades de Saúde Familiares, ${ }^{4}$ hoje perfeitamente amadurecidas nos seus aspetos organizacionais e assistenciais, apesar de barreiras políticas e financeiras à sua completa autonomização.

Atrevemo-nos a pensar que a evolução nos levará à necessária produção de conhecimento e que o novo ciclo da Medicina Geral e Familiar poderá ter a investigação como verdadeiro motor de propulsão deste movimento, permitindo um ajustamento assistencial, organizativo e político à resolução dos problemas e das necessidades reais percebidas e identificadas a nível local, regional ou nacional.

A Revista Portuguesa de Clínica Geral propõe-se cumprir um papel de relevo nesta mudança, enquanto elemento chave para uma comunicação científica efetiva. A reestruturação do organigrama operada nos últimos meses pre-

*REVISTA PORTUGUESA DE MEDICINA GERAL E FAMILIAR tende melhorar as condições de funcionalidade, desligando a administração logística da administração editorial. Apela-se a uma congregação de esforços à volta da Revista consubstanciando-se numa política editorial inclusiva, chamando novos autores que tragam qualidade e antigos autores que tragam a experiência, e com um Conselho Científico e Editorial renovado e empreendedor. É intenção da atual equipa manter a revista entre as mais lidas em Portugal e, mais além, projetar a produção científica nacional para uma internacionalização na aldeia global que é hoje o mundo científico e académico.

Neste número iniciamos uma série de pequenos contributos: a revisão das normas de publicação, que se pretendem atualizadas face aos critérios mais recentes aceites internacionalmente, e a introdução do identificador universal promovido pela ORCID®, uma organização sem fins lucrativos que ajuda a identificar cada interveniente na investigação e desenvolvimento de forma unívoca, na sua produção de conhecimento e na sua afiliação, independentemente da respetiva área de conhecimento, e ao longo do tempo. Também a publicação no formato exclusivamente digital, abandonando a impressão física em papel, e a criação de um sistema de publicitação dos artigos publicados na RPMGF através das redes sociais contribuirá para uma maior visibilidade da Revista, dos autores que em nós confiam para publicar os seus trabalhos, e, de uma forma geral, da qualidade da investigação realizada nos Cuidados de Saúde Primários.

Serão passos pequenos, mas fundamentais, neste processo de contínua melhoria da qualidade com que pretendemos marcar os próximos anos da medicina geral e familiar em Portugal.

\section{REFERÊNCIAS BIBLIOGRÁFICAS}

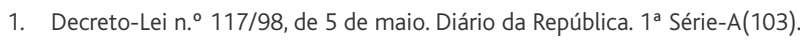

2. Hespanhol A, Malheiro A, Pinto AS. O projecto «Tubo de Ensaio»: breve história do Centro de Saúde S. João [The 'test tube' project: a brief history of the S. Joao health center]. Rev Port Clin Geral. 2002;18(3):171-86. Portuguese

3. Decreto-Lei n. ${ }^{\circ} 157 / 99$, de 10 de maio. Diário da República. $1^{\text {a }}$ Série-A(108).

4. Decreto-Lei n. ${ }^{\circ}$ 298/2007, de 22 de agosto. Diário da República. $1^{\text {a }}$ Série(161).

5. Hespanhol AP. Um ponto de situação do novo modelo editorial da revista [The current situation of the new editorial model of the RPMGF]. Rev Port Med Geral Fam. 2017;33(5):310-2. Portuguese

\section{ENDEREÇO PARA CORRESPONDÊNCIA}

Paulo Santos

E-mail: psantosdr@med.up.pt.

http://orcid.org/0000-0002-2362-5527 